\title{
Taking the Pulse of Colorado's Front Range: Developing Regional Indicators of Environmental and Quality of Life Condition
}

Indicators are routinely used to report the status and trends of human health, economy, educational achievement, and quality of life. Some environmental indicators, such as for water and air quality, are routinely reported and used to inform personal, management, or policy deci-

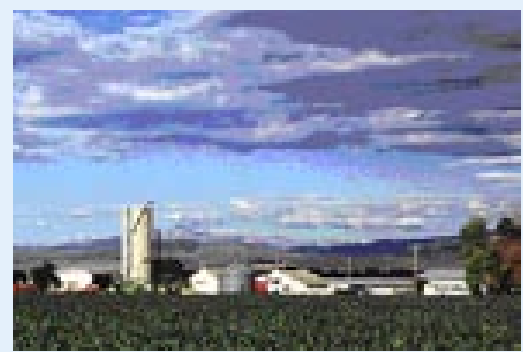

The fertile agricultural lands of the Front Range sions. Other environmental indicators, particularly those that do not relate directly to human well-being, have been harder to define, interpret, or use. These indicators may be just as useful and important in describing the ability to provide ecosystem goods and services, or less tangible quality of life measures, but they may be suspect because of the quality of data or even the source of the information.

Scientists and stakeholders alike, however, agree that mutually agreed upon indicators can be used in decision-making and can inform policy debates. The long-term goal of the project, "Taking the Pulse of Colorado's Front Range: development and application of human and environmental indicators," is to provide better scientific information in support of policy- and resource-management decisions. Critical to the success of the effort will be dialog and trust between scientists and stakeholders. The "Pulse" project is beginning with development of mutually agreeable, objective, credible, and measurable indicators of environment and quality of life.

The criterion that defines a useful indicator may differ from a scientific perspective and from a policy perspective (O'Malley and others, 2003). Scientific information is judged "good" if measurements are collected in a way that is accurate, precise, repeatable, and reflective of conditions in the real world. Policy information, on the other hand, is judged as "good" primarily if it is relevant. Does it deal directly with the question at hand? Does it illuminate the issue in ways that point to solutions? Acceptable indicators can be used over time to measure environmental change and inform policy and management.

Central to the process of indicator development is iterative collaboration among stakeholders and scientists to develop indicator sets. A workshop in November 2004 developed a first-cut list of indicators of both environmental and quality-of-life conditions for the Colorado Front Range. Participants in the workshop included farmers, water providers, state and local government representatives, private companies and not-for-profit groups as well as scientists. Subsequent discussions at the Great Plains Grassland Conference emphasized that including a variety of stakeholders from the beginning of indicator development is vital to the success of future indicator application. Indicators become viable and trustworthy if managers, scientists, and non-governmental organization members participate in indicator development from the beginning.
The "Pulse" project builds upon existing indicator development efforts [e.g., Heinz Center, 2002; NAWQA, 2005, (http://water.usgs.gov/nawqa/)]; State of the Rockies Report Card, 2004) and adds to them by including topics specific to

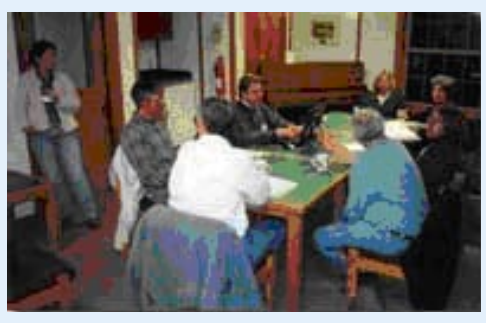
the Colorado Front Range, a region that includes the South Platte River Basin, part of the Arkansas River Basin, and major metropolitan areas from Pueblo to Fort Collins. Biomes and sectors within the region include agricultural lands, freshwaters, grasslands, urban areas, and mountains/forests. Quality-of-life indicators such as income distribution, unemployment rates, education levels, daily commute time, and natural resource development, such as the extent and location of mineral and resource extraction are considered important by regional stakeholders. A list for agricultural lands shows the types of indicators that will be used to describe the State of the Front Range (see table).

In order for indicators of condition to be judged as useful and "sound," they must be filtered through a set of stringent characteristics that can withstand scientific rigor and must accurately reflect real world conditions. Characteristics of "good" indicators include relevancy, measurability, and costeffectiveness for both collection and interpretation, among others. The "Pulse project" is moving forward to determine which data are available and where data gaps exist in order to provide decision-makers with the tools needed to address the pressing issues of environmental condition and quality of life.

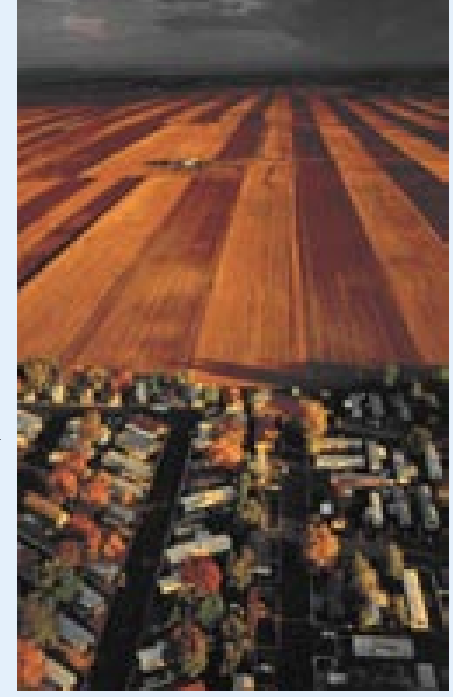

Housing development on former Front Range agricultural lands

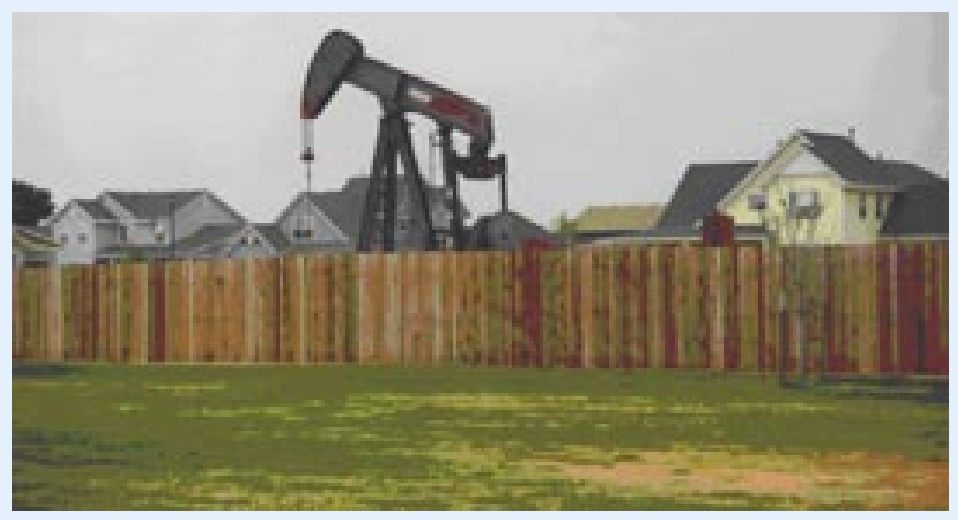

An oil-drilling pumpjack outside a Front Range neighborhood 
Table. Agricultural Land Indicators

System Dimensions

\begin{tabular}{l} 
Total cropland \\
$\begin{array}{l}\text { Shape of "natural" patches } \\
\text { in agricultural lands }\end{array}$ \\
\hline Road density \\
\hline $\begin{array}{l}\text { Land under conservation } \\
\text { management }\end{array}$ \\
\hline Fallow area
\end{tabular}

Soil erosion rates

Irrigated or dryland

Land area for energy or aggregate extraction

Land area reclaimed from extraction

Cultivated land on erodible slopes
Chemical and Physical Conditions

Nitrate, phosphorus, pesticides in streams and ground water

Stream flow

Soil organic matter

Soil salinity, metal content

Depth of a horizon

Biological
Components

Soil biological condition

Native, non-native vegeta tion

Ground cover type: live vegetation, litter, mulch

Animal species and numbers

Animal unit months/area

Stream and riparian habitat quality

Topographic relief

Stream sediment load
Human Uses

Major crop yields

Agricultural inputs and outputs

Monetary value of production ship

Recreation on farmlands

Hunting harvest

Land and water prices

Irrigation type (flood, pivot, drip)
Quality of Life

Age of operator

Distance to schools, health care

Corporate vs. private owner-

Education attainment

Employment, percent and by sector

Income distribution

Depth to groundwater

Number and type of wells

Atmospheric dust concentration, composition

\section{Criteria that make a good indicator (from November 2004 workshop)}

- Relevant

- Measurable

- Repeatable

- Cost effective
- Understandable

- Transparent

- Verifiable
- Sensitive to change

- Scale appropriate

- Quantifiable

For more information on the Pulse Project goals, framework, workshop attendees, and lists of environmental indicators and characteristics of indicators developed during the workshop, please go to: http://rockyweb.cr.usgs.gov/Pulse/

\section{References Cited}

Colorado College State of the Rockies Report Card., 2004., www.coloradocollege.edu/stateoftherockies

H. John Heinz III Center, 2002, The state of the nation's ecosystems: Measuring the lands, waters, and living resources of the United States: New York, Cambridge University Press.

NAWQA, National Water Quality Assessment Program: U.S. Geological Survey, http://water.usgs.gov/nawqa/

O’Malley, R.K., Cavendare-Bares, K., Clark, W.C., 2003, Providing "better" data: not as simple as it might seem: Environment, v. 45 , p. $8-18$.

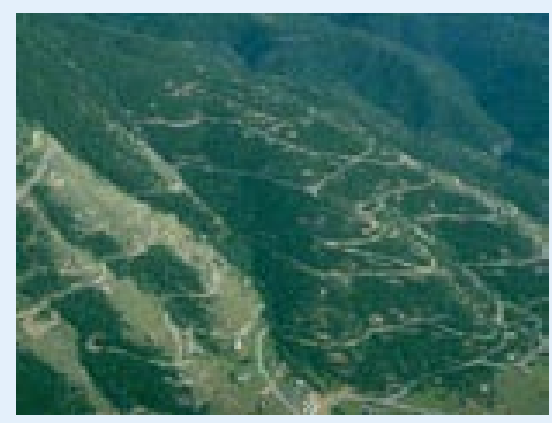

Housing development in the Front Range foothills

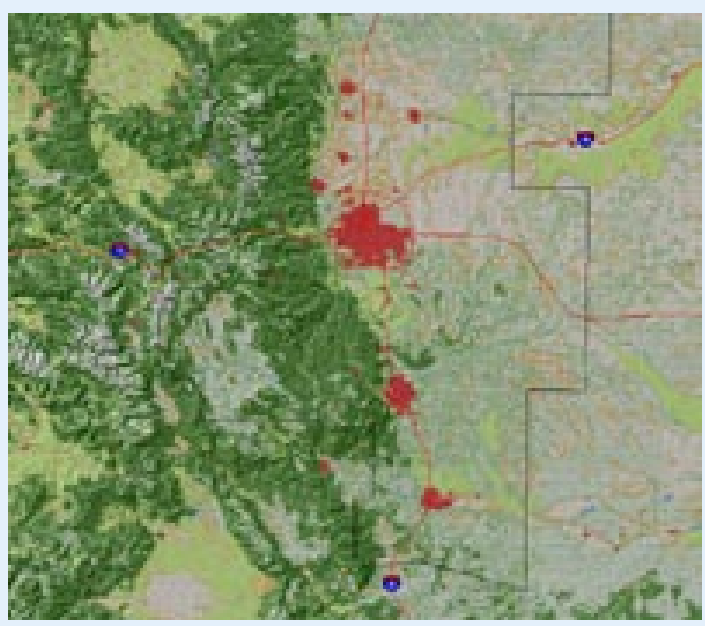

